Article

\title{
Empirical Study on the Factors Affecting Individuals' Switching Intention to Augmented/Virtual Reality Content Services Based on Push-Pull-Mooring Theory
}

\author{
Sanghyun Kim ${ }^{1, *}$, Moon Jong Choi ${ }^{2}$ and Jae Sung Choi ${ }^{2}$ \\ 1 School of Business Administration, Kyungpook National University, Daegu 41566, Korea \\ 2 Department of Computer Science and Engineering, Sunmoon University, Asan-si 31460, Korea; \\ mjchoi0@gmail.com (M.J.C.); jschoi@sunmoon.ac.kr (J.S.C.) \\ * Correspondence: ksh@knu.ac.kr; Tel.: +82-53-950-5877
}

Received: 4 December 2019; Accepted: 27 December 2019; Published: 30 December 2019

\begin{abstract}
New technologies are driving rapid change and innovation in the industrial structure. In this environment, individuals' use of contents also changes remarkably. This study aims to empirically prove why individuals switch from traditional to augmented/virtual reality (AR/VR) content services. We propose a research model and hypotheses based on data collected from existing research and AR/VR users. To explain individuals' switch, we include three constructs for the push effects (low usefulness, functional simplicity, and perceived inefficiency) and three constructs for the pull effects (interactivity, experienceability, and amplified enjoyment) in our proposed model based on the most valid push-pull-mooring. Furthermore, we propose personal innovativeness as a mooring effect on the relationships between push/pull effects and switching intention to AR/VR content services. The data $(n=465)$ from actual AR/VR users were collected and analyzed using structural equation modeling with AMOS 22.0. Results empirically prove that all push/pull constructs, with the exception of perceived inefficiency, have a significant impact on switching intention. Moreover, a mooring effect-personal innovativeness—strengthens all paths in the research model, except that between perceived inefficiency and switching intention. The findings of this study would provide theoretical and practical implications for understanding individuals' perceptions regarding AR/VR content services.
\end{abstract}

Keywords: augmented reality; virtual reality; push-pull-mooring theory; switching intention

\section{Introduction}

Future societal changes due to a new era of industrial revolution, often called the fourth industrial revolution, are expected to greatly affect technology, industrial structure, and employment structure. Smart business models with new technologies changing the industrial structure through the convergence between technology and industry, and individual perception related to such convergence, will emerge in various ways by incorporating the latest information technology (IT), including augmented/virtual reality (AR/VR) [1]. AR/VR or mixed reality (MR) is becoming a mainstream and valuable topic in many industries. In addition, these technologies are expected to be applied in various fields such as medical, defense, marketing, education, fashion, art, gaming, entertainment, and many more. The market for information communication technology converged contents is rapidly growing due to the technological convergence between IT and traditional industries [2]. In other words, individuals can see that the use of content services through AR/VR compared with traditional content is becoming more common in an environment where technology is converged.

Reflecting this trend, AR/VR users continue to increase. According to Statista [3], less than one million VR/VR users were recorded in 2014. However, the number had rapidly increased to more 
than 150 million users by 2018. This number is expected to grow even higher over the coming years. Moreover, Zion Market Research [4] reports that the market value of AR/VR was approximately \$2 billion in 2016 and is expected to reach $\$ 26.8$ billion by 2022 . These statistics imply that the development of AR/VR-related technologies attracts much attention from various industries and individuals, and that various contents are provided in the AR/VR environment. As the number of AR/VR users has increased, various studies have been conducted. However, previous studies related to AR/VR $[5,6]$ have focused on its technical aspects, case studies, and applications (in several areas, including medical and education). When a new technology is developed, various technical studies related to that technology become essential. In this respect, technical research on AR/VR is also an important topic. For example, Fagan et al. [7] explored nursing students' perceptions of a VR simulation that enables students to learn how to use a medical emergency crash cart.

However, to activate the use of content services provided in an already developed technological environment such as AR/VR, it is necessary to have a clear understanding of why AR/VR content users have switched from traditional content services to AR/VR content. Therefore, it is essential not only to conduct research on technology and markets for the continuous integration of related technologies into various fields, but also to understand why individuals are switching from non-AR/VR to AR/VR content services. Therefore, this study exhibits two important points of rationality: the increasing trend of AR/VR content service usage and the limitations of existing AR/VR research. Based on these points, this study examines what factors affect individuals' switching intention from non-AR/VR to AR/VR content services based on the pull-push-mooring (PPM) theory and previous studies. Thus, we would like to provide empirical evidence for the following four research questions:

(1) What are the trends in AR/VR usage?

(2) What are the situational factors related to non-AR/VR and AR/VR?

(3) How do non-AR/VR and AR/VR context variables affect an individual's intention to switch to AR/VR content services?

(4) Does personal innovativeness enhance the relationships between the push/pull variables and intention to switch to AR/VR services?

To empirically address these research questions, we collected data from actual users of AR/VR content services through a survey. In addition, we propose a research model that includes three push variables (low usefulness, functional simplicity, and perceived inefficiency) and three pull variables (interactivity, experienceability, and amplified enjoyment). Additionally, the mooring effect of personal innovativeness is proposed as a moderating effect for the relationship between the push/pull variables and switching intention to AR/VR services. Validation of the proposed research model is expected to improve the understanding of the reasons for individuals' switch to AR/VR services.

\section{Related Works and Hypotheses}

\subsection{Augmented/Virtual Reality}

The term virtual reality (VR) first appeared in 1938, but the product was embodied in VR goggles and gloves developed in 1985 by the VPL lab at Jarren Rainier, USA. VR is an interface environment between humans and computers that supports user interaction with computing technology to implement specific environments and situations [8]. Such VR includes (1) augmented reality that adds virtual elements to the real environment, (2) augmented virtuality that adds reality to the virtual world, and (3) a virtual environment that implements the real environment in the virtual environment. Previously, it was used as a surgical practice or training to control tanks and aircraft. However, the post-smartphone industry has introduced head-mounted display type mobile devices that can interact with high-performance PCs, game consoles, and smartphones to enjoy virtual reality content.

With an increasing interest in AR/VR content services, AR/VR has been applied in various fields. For example, Noh et al. [9] conducted an experimental study to investigate the effects of augmented reality 
content-based instruction on academic achievement, learning interest, and immersion. They found that the AR-based instruction group had a higher performance than the textbook-based instruction group in their class activities. Meanwhile, Nee et al. [10] studied the research and development of AR applications in design and manufacturing. They reviewed the initial AR development along with hardware and software tools related to AR. In addition, they presented various studies of design and manufacturing activities with AR tools and techniques. In addition, Han [11] investigated the academic stress and the immersion in learning associated with AR/VR-based instructions compared with traditional approaches and found that students feel more stressed with AR/VR-based lessons compared with the traditional ones.

Another application of AR/VR content is in tourism. For example, An and Lee [12] investigated the relationship between the sense of stimulation of VR and experiential value as well as satisfaction. Furthermore, the study tested the casual relationship between satisfaction and visiting intention to a destination featured in the VR. The results reveal that sense had a positive impact on experiential value (composed of extrinsic and intrinsic value), which in turn had a positive impact on satisfaction in both the travel fair and VR experience zone. Finally, satisfaction is positively associated with intention to visit. Although research on the behavior and perception of users related to the use of AR/VR content services has been conducted, there is no empirical study on why users switch to AR/VR content services. More individuals are expected to switch to AR/VR contents for various reasons; hence, it is very important to investigate reasons for switching to AR/VR content services.

\subsection{Push-Pull-Mooring (PPM) Framework}

Migration refers to the movement of humans between two places for a certain period, and the theory explaining the law of migration begins with the Law of Migration published by Ravenstein [13], which explained that human movement is caused by distance, flow of movement, technological development, and economic causes. Lee [14] later stated that a clear presentation of the place of origin and the destination to which it was to go should be premised. He also argued that factors related to the original place and destination and factors affecting the movement between the two places would affect migration. PPM is based on the theory of migration, which refers to the movement of individuals between two places at specific times $[15,16]$. Bogue [16] explained migration by dividing the factors that affect human migration into the push effect and pull effect. Here, the push effect is related to the factors pushing away from the original place of residence, whereas the pull effect is related to the factors pulling to a new destination $[15,16]$. The Push-Pull paradigm explains that individuals consider moving between places because of the interaction between these two factors. In other words, if people are aware of the negative factors in the place where they originally reside such as natural disasters, lack of employment and marriage opportunities, and income decline, or the positive factors in new destinations such as better employment opportunities, recognition of the natural environment and living conditions, this can lead to decision-making about migration through the interaction between these factors [16].

However, the interaction between the push and pull effects presented by the Push-Pull paradigm was not enough to explain the migration problem. Hence, a mooring effect was added to the Push-Pull paradigm to explain migration more effectively $[15,17]$. The mooring effect, described as "intervening obstacles," is related to the situational factors that facilitate the migration of human beings, thereby expediting human migration or vice versa. In other words, the variables related to personal situations, psychological factors, environment, culture, lifestyle, and social influences are factors that supplement the push and pull effects in the PPM framework [15,17].

\subsection{Research Based on PPM}

Prior studies on the PPM framework argue that these three factors can be effectively predicted in human migration decisions and behavior only when properly considered [17]. The PPM framework can also explain the transition of a product or service from its original place of residence to a new 
destination. Thus, in the field of marketing and information systems (IS), the PPM framework has been recognized as a useful theoretical framework for explaining transition behaviors for services and service providers [18-21]. For example, Hsieh et al. [22] examined the switching behavior of an individual's voluntary online service subscription based on the PPM model. Through empirical analysis, they found that push effects (weak connectivity and writing anxiety), pull effects (relative usefulness and enjoyment), and mooring effects (transition costs and experience) influenced individuals' transition to online subscription services. The PPM model could be a useful theoretical framework for looking at the factors that influence the use of online service subscriptions.

Sun et al. [20] applied the PPM model to the study of the switching behavior of mobile instant messaging services. They explained that the PPM model is a useful theory for explaining human migration behavior and argued that the PPM model could also help in understanding the determinants of switching behavior in IS research. In addition, this theory is useful for understanding not only the inflow of new users but also the determinants of maintaining existing users. In addition, Chang et al. [18] conducted an empirical analysis by applying the PPM model to a study to examine the switching of consumer channels between offline stores and mobile stores. The findings of the study show that the push effects, including the value of products and services obtained from physical stores and information retrieval benefits, and the pull factor (customers' evaluation of the attractiveness of mobile stores) have a significant effect on conversion intention. In addition, mobile shopping self-efficacy was found to reinforce the relationship between the push/pull factor and conversion intention as a variable for the mooring effect. Chang et al. [18] argue that the PPM model can be a useful theory for understanding the individual's conversion behavior, and that the PPM model can be applied and extended to explain various conversion behaviors of consumers.

Recently, Cheng et al. [19] examined the voluntary transition behavior of mobile cloud storage service users in the Chinese market based on the PPM model. They found that push factors (privacy risks and security risks), pull factors (network size, complementarity, usefulness, technical compatibility, lifestyle compatibility, and enjoyment), and mooring effects (habits and switching costs) have a significant impact on switching intention. Furthermore, Wang et al. [21] applied the PPM model to an empirical study of the switching behavior of mobile payment applications. Research shows that privacy concerns (push factors) of mobile payment applications, monetary rewards for alternatives (pull factors), and perceived economic value, past investments, and technical self-efficacy (mooring factors) have a significant impact on conversion behavior. In addition, various contextual variables can be proposed based on the PPM model to explain the transition behavior more effectively.

\section{Research Model and Hypotheses}

\subsection{Research Model}

Based on PPM, we proposed a research model and hypotheses to be tested using the data collected in this study. In the process of developing the research model, we conducted interviews with actual AR/VR users to have a better understanding of their reasons for moving away from non-AR/VR content services and switching to AR/VR content services. In addition, push/pull and mooring variables were proposed through previous studies [18-20] on service and technology switch. Thus, the proposed research includes three push effects (low usefulness, functional simplicity, and perceived inefficiency) and three pull effects (interactivity, experienceability, and amplified enjoyment), which have a positive impact on intention to switch to AR/VR content services. For the mooring effect, we proposed personal innovativeness, which enhances the relationships between push/pull constructs and switching intention to AR/VR content services. Figure 1 presents the proposed research model and hypotheses. 


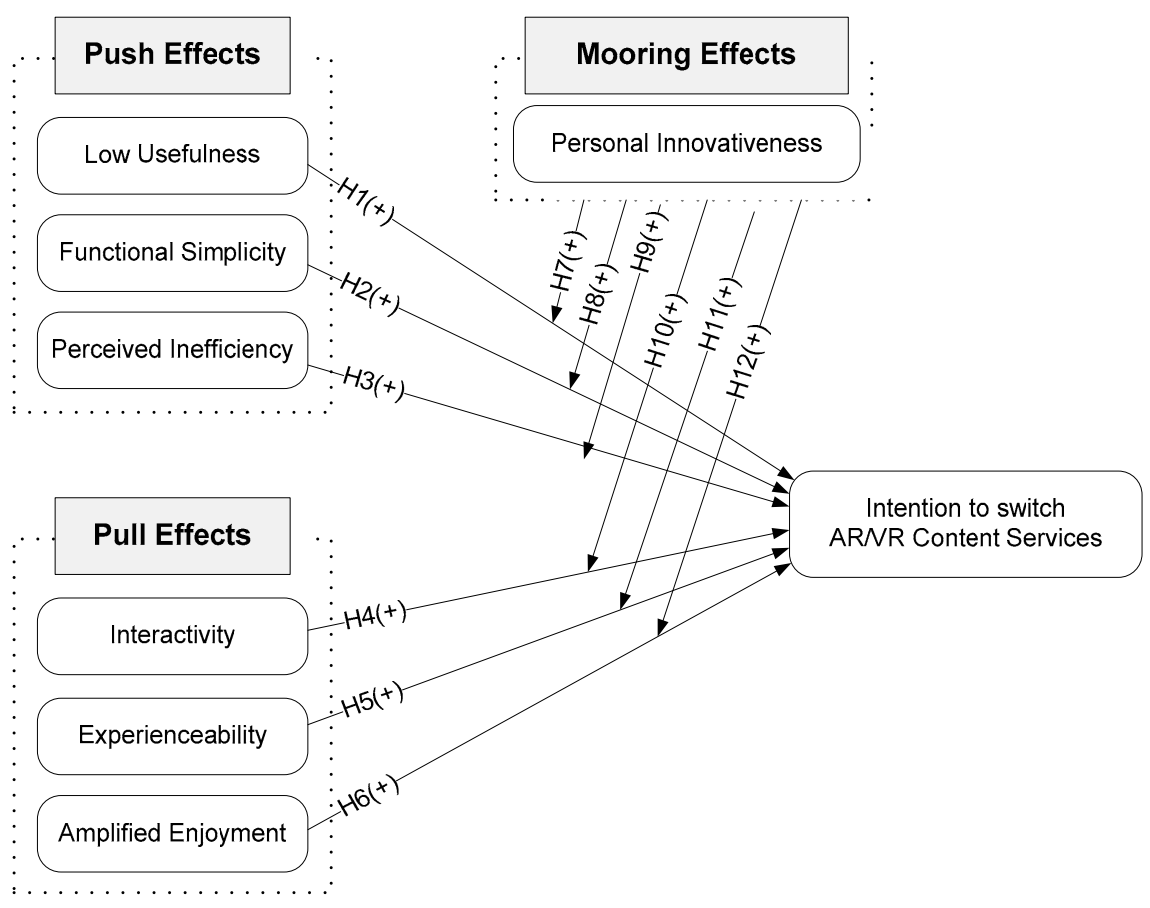

Figure 1. Research model and hypotheses.

\subsection{Hypothesis Development}

A push factor refers to a negative element of perception or weakness of the current place that causes humans to move from their original place of residence to a new one $[15,17,20]$. Applying this concept of push to this study, we define the push element as users switching to AR/VR content services due to the negativity or limitation of non-AR/VR content services. Therefore, based on IT research and the characteristics of non-AR/VR content services, this study suggests three constructs as the push factors: low usefulness, functional simplicity, and perceived inefficiency. These variables are considered to be the push factors that have a significant impact on the technology transition in previous studies. For example, Cheng et al. [19] argued that when a user perceives that a particular technology or service is not useful, the intention to switch to the new technology would increase. In addition, when the functional simplicity or inefficiency of the current content service is recognized, users have a high intention to switch to a new type of content service such as AR/VR [21,22].

First, low usefulness is defined as the degree to which users perceive that non-AR/VR contents will not offer expected benefits and will not be useful for their task [23]. If individuals perceive that the traditional content services are limited in practicality, the negative perception may lead to negative behavior in terms of a lower intention to use them [23,24]. In addition, Alter [25] claimed that individuals consistently evaluate the system and service they are currently using. As individuals do not expect such systems and services to support their tasks, they tend to move away from them to find those that are more useful. That is, individuals who experience the limitation, ineffectiveness, and less usefulness of the traditional content services in performing their tasks or for achieving their desired goals attempt to find a new content service and have a high willingness to switch. Consequently, when low usefulness is anticipated, user switching behavior will occur [26]. Thus, based on prior research, the first hypothesis is proposed:

Hypothesis 1 (H1). Low usefulness is positively associated with switching intention to AR/VR content services.

The second construct, within the push effects, is functional simplicity, which is defined as the extent to which content users perceive the diversity of content and functionality and the degree of dynamicity when using non-AR/VR services. Functional simplicity is similar in both user-friendliness 
and its semantic positiveness. Although the simplicity of the system may be essential to attract positive reactions from users in a particular IS, the simplicity in the use of the content may cause users to lose interest [27]. Bolz [28] claimed that the functional simplicity of the system structure and the interface in using the system makes it easy to use, but such simplicity, particularly in the use of contents, makes the content difficult to understand. Traditional content services provide users with games and learning in a two-dimensional structure. However, in the new technology environment based on AR/VR, users can realize that the existing content service has a limited purpose because it provides multidimensional content. In this regard, Maican and Lixandroiu [29] claim that the simplicity of the traditional content services makes users feel less excited, which becomes the main reason for them to find a new content service. Therefore, based on these claims, we propose the following research hypothesis:

Hypothesis 2 (H2). Functional simplicity is positively associated with switching intention to AR/VR content services.

Perceived inefficiency refers to the degree of negative experience such as the insufficiency of content, time wasted, and others that individuals perceive from their use of traditional content in their work. Similarly, a prior study [30] has defined perceived inefficiency as one's feelings of inadequacy and incompetence when performing tasks at work. In general, individuals perceive a high level of efficiency with a new technology or service. However, due to technical constraints, traditional content is constrained by users' various purposes [31], which makes individuals constantly look for new content services. In addition, Trappey and Trappey [32] claim that users of traditional (flat) contents often face a difficult time understanding contents because of a lack of content transparency. Such inadequate content transparency forces users to refrain from using the content. Finally, individuals' productivity with traditional contents is limited compared with AR/VR contents, resulting in the traditional content users switching to more innovative content services [33]. Accordingly, the third hypothesis is proposed:

Hypothesis 3 (H3). Perceived inefficiency is positively associated with switching intention to AR/VR content services.

Pull factors are the positive factors in a new place that leads people to move to that place. Thus, pull effects in this study are positive factors related to the characteristics of AR/VR contents that cause the transition from traditional contents to AR/VR contents [20,34]. Based on prior studies and data from actual AR/VR users, we suggest three constructs-interactivity, experienceability, and amplified enjoyment-as the pull factors that have a positive impact on intention to switch to AR/VR content services. Prior studies $[19,21]$ claim that AR/VR content users value these three factors most importantly among various characteristics of AR/VR contents.

First, many IT studies found that interactivity is a key determinant affecting individuals' behaviors $[35,36]$. AR/VR contents make the concept of interactivity much clearer than contents in the traditional environment. This study defines interactivity as the extent to which users can participate in modifying the form and contents of AR/VR environment in real time (Laurel, 1986). In particular, the interaction is crucial for users of AR/VR contents when sharing information (e.g., trips), playing games, and learning with others. Bruckmen and Jensen [37] claim that if individuals have a high perception that they can establish a connection with AR/VR contents, they will have a high intention to use it. Other studies [38,39] claim that interactivity is the mutual mediated interaction and considered a crucial impact in developing individuals' relationships and experiences, which eventually has extreme power in deciding their behaviors. In other words, the ability to interact with AR/VR contents can have a great influence on users' desire to switch from traditional contents to AR/VR contents. Thus, the following hypothesis is established:

Hypothesis 4 (H4). Interactivity is positively associated with switching intention to AR/VR content services. 
Second, experienceability is a new concept that is only applicable in AR/VR contents. It is defined as the extent to which AR/VR content users can experience the content similarly to the real-world situation when using the content. Whether individuals play a game, take pictures, or simulate things or design, they feel these contents as real-world elements. Thus, what users are doing becomes a reality within the AR/VR content environment. Chung et al. [40] investigated users' intention to visit a destination with AR application as smart tourism. They found various reasons behind tourists' use of AR application. Among them, they cited the opportunity for travelers to experience the travel location before actually visiting it in AR/VR contents as an essential reason. Furthermore, Formsma [41] argues that traditional content is static whereas AR/VR content is dynamic; hence, users can have a dynamic experience. Market Advisor [42] claims that experiencing various contents from an AR/VR environment becomes a driver for users to switch to AR/VR because it allows users to have a real-time camera view of a particular place or space from devices such as smartphones, tablets, and laptops. Moreover, an AR/VR content environment imposes digital objects, often called experiences, into the real world to give a three-dimensional feeling to the entire experience, which is unique compared with simply watching them on flat contents, no matter how graphically good those contents are. Thus, with the importance of experience in using contents, the following hypothesis is proposed:

Hypothesis 5 (H5). Experienceability is positively associated with switching intention to AR/VR content services.

Another construct in the pull effects is amplified enjoyment. Enjoyment is often mentioned to explain various behaviors of users in utilizing IT $[43,44]$. In the literature, enjoyment referring to an individual's subjective experience of a human-computer interaction is defined as the degree to which an individual believes that the activity of using technology or service is perceived as enjoyable in its own right, despite any performance consequences that may be anticipated [44]. Based on this operational definition, this study defines amplified enjoyment as the relative magnitude of enjoyment perceived by AR/VR content users. In other words, amplified enjoyment is the maximum enjoyment that users can feel from AR/VR contents, but not from flat contents.

It is natural for users to move to contents that bring greater enjoyment and happiness in using them. Therefore, greater enjoyment is argued to be a direct factor in individuals' behaviors toward technologies [45]. Furthermore, Hwang and Kim [46] claimed that affective outcomes, including enjoyment resulting from a certain technology, are often caused by affective influences and incorporating it into judgmental processes. That is, when individuals experience psychological reactions such as greater enjoyment, they tend to make a decision based on such feelings. Hence, when AR/VR content users will be able to experience greater enjoyment from this service, their switching intention to the service will be greater, and thereby the following hypothesis is proposed:

Hypothesis 6 (H6). Amplified enjoyment is positively associated with switching intention to AR/VR content services.

\subsection{The Moderating Effect of Personal Innovativeness}

In this study, personal innovativeness is defined as individuals' voluntary intention to switch to AR/VR content services based on the prior definition [47]. Innovative individuals are often very inclined to accept new technologies. They are satisfied with new technology usage for their tasks [48]. Particularly, AR/VR contents offer many benefits to users compared with flat contents. Wu and Wang [48] claim that personal innovation tends to have a greater impact, particularly when limitations or advantages of certain content services exist. For example, flat contents are very limited in terms of usefulness, variety, and efficiency for users in completing a task. In this situation, innovative users are constantly looking for new types of content services [47]. Therefore, when users perceive various factors for them to move away from flat contents, they are very inclined to switch to AR/VR contents. 
Moreover, if the user is very innovative in this relationship, the intention to switch is higher [49]. Based on these claims, the following three hypotheses are developed.

Hypothesis 7 (H7). Personal innovativeness strengthens the relationship between low usefulness and intention to switch to AR/VR content services.

Hypothesis 8 (H8). Personal innovativeness strengthens the relationship between functional simplicity and intention to switch to AR/VR content services.

Hypothesis 9 (H9). Personal innovativeness strengthens the relationship between perceived inefficiency and intention to switch to $A R / V R$ content services.

In addition, personal innovativeness enhances the relationships between pull effects (interactivity, experienceability, and amplified enjoyment) and switching intention to AR/VR content services. The idea that personal innovation reinforces this relationship underlies the thinking of innovative content users that switching to new content services is essential to experience new functions or obtain opportunities for new experiences [50]. In other words, the pull effects of AR/VR contents may not be sufficient to explain users' switching intention to AR/VR contents without an individual's characteristics such as personal innovativeness [51]. Therefore, when switching to a new content service, the user's personal characteristics must be considered. Among these personal characteristics, an individual's innovation further expands the advantages of AR/VR contents and, consequently, has a very important influence on switching to the content service [52]. Thus, emphasizing the importance of personal innovativeness, we proposed the following hypotheses:

Hypothesis 10 (H10). Personal innovativeness strengthens the relationship between interactivity and intention to switch to $A R / V R$ content services.

Hypothesis 11 (H11). Personal innovativeness strengthens the relationship between experienceability and intention to switch to AR/VR content services.

Hypothesis 12 (H12). Personal innovativeness strengthens the relationship between amplified enjoyment and intention to switch to AR/VR content services.

\section{Methodology and Analysis}

\subsection{Samples}

The data for verifying the research model proposed in this study were obtained from individuals who switched from flat contents to AR/VR contents and who are currently using them. In particular, the validity of the research results can be improved by limiting the survey data to individuals who voluntarily switched to AR/VR content services. The involuntary switch to AR/VR services may cause difficulty in grasping the true meaning of the switching intention because it is caused by external influences rather than a user-centered switch from specific IT to a new one. In this regard, this study investigated whether the AR/VR content service switch is involuntary or voluntary. Those responses marked as involuntary switch were discarded. Data were collected in public places (libraries, terminals, downtown, etc.) for two months. A total of 478 responses were collected. However, we excluded 13 incomplete responses; thus, 465 responses were used for the final analysis.

Regarding the demographic information of the participants, 286 responses $(61.51 \%)$ were male, and $179(38.49 \%)$ were female. Participants were diverse in age, ranging from 15 years old to more than 50 years old, with 29 years old being the average age. Young people in their teens and $20 \mathrm{~s}(16.77 \%)$ had the largest share of AR/VR content usage, followed by 30s (16.77\%). Furthermore, $23.23 \%$ of 
respondents were in their 40s and 50s, indicating that AR/VR content is being used across all ages. Next, the occupation of the survey participants varied from student to professional, wherein most participants were students (32.69\%), followed by company employee (31.83\%), implying that AR/VR contents are used in many fields regardless of occupations. By using the data collected from various ages and occupations for analysis, we can generalize the data. Participants have used AR/VR contents for as little as one year to as much as 5 years. Among them, one to three years (43.66\%) was the highest. Finally, the participants used AR/VR contents for various purposes. For example, $83.66 \%$ of participants use AR/VR entertainment contents, followed by social life (52.47\%), including shopping, hobby, and travel. Table 1 shows the profiles of the respondents.

Table 1. Demographic characteristics $(n=465)$.

\begin{tabular}{|c|c|c|c|}
\hline \multicolumn{2}{|c|}{ Demographic Categories } & \multirow{3}{*}{$\begin{array}{c}\text { Frequency } \\
286 \\
179\end{array}$} & \multirow{3}{*}{$\begin{array}{c}\text { Percentage (\%) } \\
61.51 \\
38.49\end{array}$} \\
\hline Conder & Male & & \\
\hline Gender & Female & & \\
\hline \multirow{5}{*}{ Age (years) } & $15-19$ & 82 & 17.63 \\
\hline & $20-29$ & 197 & 42.37 \\
\hline & $30-39$ & 78 & 16.77 \\
\hline & $40-49$ & 55 & 11.83 \\
\hline & $50+$ & 53 & 11.40 \\
\hline \multirow{5}{*}{ Occupation } & Student & 152 & 32.69 \\
\hline & Company employee & 148 & 31.83 \\
\hline & Self-employed & 91 & 19.57 \\
\hline & Professional & 59 & 12.69 \\
\hline & Other & 15 & 3.23 \\
\hline \multirow{5}{*}{$\begin{array}{l}\text { Devices used for AR/VR } \\
\text { contents }\end{array}$} & Smartphone & 428 & 92.04 \\
\hline & Head-mounted display (HMD) & 337 & 72.47 \\
\hline & Smart TV/Smart Blackboard & 256 & 55.05 \\
\hline & Tablet PC & 350 & 75.27 \\
\hline & Others & 12 & 2.58 \\
\hline \multirow{4}{*}{$\begin{array}{l}\text { Length of using AR/VR } \\
\text { service after switching to } \\
\text { the service }\end{array}$} & Less than 1 year & 66 & 14.19 \\
\hline & $1-3$ years & 203 & 43.66 \\
\hline & $3-5$ years & 137 & 29.46 \\
\hline & More than 5 years & 59 & 12.69 \\
\hline \multirow{5}{*}{$\begin{array}{l}\text { AR/VR contents used or in } \\
\text { use (multiple responses) }\end{array}$} & Entertainment & 389 & 83.66 \\
\hline & Education & 165 & 35.48 \\
\hline & Content development & 50 & 10.75 \\
\hline & $\begin{array}{c}\text { Social life (e.g., shopping, hobby, } \\
\text { travel, etc.) }\end{array}$ & 244 & 52.47 \\
\hline & Other & 53 & 11.40 \\
\hline
\end{tabular}

\subsection{Development of Measures}

Items for measuring study variables were developed in several steps. First, items related to the study variables were derived based on the existing research. All these items were transformed into a seven-point Likert scale, ranging from "(1) strongly disagree" to "(7) strongly agree" and modified according to the contents of this study. Next, the content validity test of all measurement items was conducted. Content validity was examined by researchers in the IT field (e.g., IS professors and graduate doctoral students) to verify contextual sophistication for each item. Finally, for the statistical verification of the developed measurement items, a pre-test was conducted to verify the reliability and validity of all measures. A total of 25 responses from AR/VR users were evaluated, and there were no items that would impede the reliability and validity. The measurement items and related studies for measuring the study variables of this study are shown in Table 2. 
Table 2. Measures and related studies.

\begin{tabular}{|c|c|c|}
\hline Construct & Measures & Related Studies \\
\hline \multirow[b]{2}{*}{ Low usefulness } & I think that non-AR/VR content services ... & \multirow{2}{*}{$\begin{array}{l}\text { Bhattacherjee and } \\
\text { Hikmet [23] } \\
\text { Lapointe and } \\
\text { Rivard [26] }\end{array}$} \\
\hline & $\begin{array}{l}\text { - } \quad \text { Are limited in performing my tasks. } \\
\text { - } \quad \text { Would not enhance effectiveness in my tasks. } \\
\text { - } \quad \text { Would be less useful for my desired purposes overall. }\end{array}$ & \\
\hline $\begin{array}{l}\text { Functional } \\
\text { simplicity }\end{array}$ & $\begin{array}{l}\text { I think that non-AR/VR content services are limited } \\
\text { in functions. } \\
\text { I can enjoy only a two-dimensional aspect of a service } \\
\text { with non-AR/VR contents. } \\
\text { Since there is no virtual environment with a } \\
\text { non-AR/VR content service, which makes the content } \\
\text { service simple, I feel less excited about the service. }\end{array}$ & $\begin{array}{l}\text { Permatasari and } \\
\text { Prajanti [27] } \\
\text { Maican and } \\
\text { Lixandroiu [29] }\end{array}$ \\
\hline $\begin{array}{l}\text { Perceived } \\
\text { inefficiency }\end{array}$ & $\begin{array}{l}\text { I have to spend more time with non-AR/VR contents } \\
\text { in understanding materials. } \\
\text { I believe that there is a lack of content transparency } \\
\text { with non-AR/VR services. } \\
\text { My productivity with non-AR/VR contents is limited } \\
\text { compared with AR/VR contents. }\end{array}$ & $\begin{array}{l}\text { Maslach et al. [30] } \\
\text { Mujber and Szecsi } \\
\text { [33] }\end{array}$ \\
\hline Interactivity & $\begin{array}{l}\text { I can interact with other contents through an } \\
\text { AR/VR environment. } \\
\text { AR/VR content services offer simultaneous real-time } \\
\text { communication for users and content providers. } \\
\text { AR/VR content services offer mutual communication } \\
\text { between users and content providers and between } \\
\text { users and others. }\end{array}$ & $\begin{array}{l}\text { Merrilees [39] } \\
\text { Lii et al. [53] }\end{array}$ \\
\hline Experienceability & $\begin{array}{l}\text { - I can experience contents very well with } \\
\text { AR/VAR services. } \\
\text { - I feel that I am included in the contents when I use } \\
\text { AR/VR content services. } \\
\text { - I enjoy using AR/VR services because I can feel the } \\
\text { reality of the content. }\end{array}$ & Hsieh et al. [22] \\
\hline $\begin{array}{l}\text { Amplified } \\
\text { enjoyment }\end{array}$ & $\begin{array}{l}\text { - I find AR/VR contents more entertaining. } \\
\text { - Sometimes, I am extremely excited about using } \\
\text { contents through an AR/VR environment. } \\
\text { It is obvious that AR/VR contents are much more } \\
\text { enjoyable than contents in other environments. }\end{array}$ & $\begin{array}{l}\text { Hou et al. [34] } \\
\text { Xu et al. [54] }\end{array}$ \\
\hline $\begin{array}{l}\text { Personal } \\
\text { innovativeness }\end{array}$ & $\begin{array}{l}\text { I like to try new ways of various content use. } \\
\text { I like something new and different when } \\
\text { enjoying contents. } \\
\text { I am the kind of person who tries something new } \\
\text { earlier than others. }\end{array}$ & $\begin{array}{c}\text { Lu et al. [50] } \\
\text { Park and Ryoo [51] }\end{array}$ \\
\hline $\begin{array}{l}\text { Intention to switch } \\
\text { to AR/VR content } \\
\text { services }\end{array}$ & $\begin{array}{l}\text { - I am very inclined to encounter many contents I can } \\
\text { use in the AR/VR environment. } \\
\text { - I am willing to switch to AR/VR content services. } \\
\text { - I will soon be using AR/VR content services. } \\
\text { - I like the content in the AR/VR environment } \\
\text { more generally. }\end{array}$ & $\begin{array}{l}\text { Hsieh et al. [22] } \\
\text { Zhang et al. [55] }\end{array}$ \\
\hline
\end{tabular}

\subsection{Analysis of the Measurement Model}

Before testing the structural model (research hypothesis) proposed in this study, the reliability and validity (convergent validity and discriminant validity) of the measurement items were verified based on several indicators such as factor loading derived from confirmatory factor analysis (CFA) verification and Cronbach's alpha. For this purpose, we used SPSS AMOS 22.0. First, the suitability of 
the measurement model was verified. The criteria for goodness-of-fit were based on several indicators, including Normed Fit Index (NFI), Goodness of Fix Index (GFI), Adjusted Goodness of Fit Index (AGFI), Comparative Fit Index (CFI), Root Mean Square Error of Approximation (RMSEA), and the relative chi-square ( $\left.\chi^{2} / \mathrm{df}\right)$ resulting from CFA verification. The threshold of NFI, GFI, and CFI should be greater than 0.9, and AGFI should be greater than 0.8 [56]. Furthermore, RMSEA should be around 0.08 or less than 0.05 [57], and the acceptable relative chi-square $\left(\chi^{2} / \mathrm{df}\right)$ is as high as 5 [58].

The result shows that two indices (NFI and GFI) were below the recommended value. By investigating the modification index (MI), one of the outputs from the CFA test, one item (swi4) had cross-loading issues, implying that this item also measured another latent construct in the research model. Thus, after removing this item, the measurement model (Model 2) was re-evaluated. The re-evaluation result shows that all indices exceed the threshold. Table 3 summarizes the results of the fitness test of the measurement model.

Table 3. Fitness test of the measurement model.

\begin{tabular}{ccccccc}
\hline Model & NFI & GFI & AGFI & CFI & RMSEA & $\chi^{2} / \mathbf{d f}$ \\
\hline Initial model & 0.859 & 0.886 & 0.827 & 0.915 & 0.047 & 2.124 \\
Revised model & 0.910 & 0.927 & 0.886 & 0.932 & 0.041 & 1.963 \\
Threshold & $\geq 0.9$ & $\geq 0.9$ & $\geq 0.8$ & $\geq 0.9$ & $\leq 0.05$ & $\geq 5.0$ \\
\hline
\end{tabular}

Note: swi4 was dropped in the revised model analysis.

Next, the reliability and two types of validity (convergent validity and discriminant validity) were analyzed. Cronbach's alpha was used to test reliability, which tests the internal consistency of measures. The value of Cronbach's alpha should be greater than 0.7 in a study using individual data [59]. As shown in Table 4, the alpha of all latent constructs exceeds the threshold, thereby confirming the internal consistency of the measurement model. Convergent validity verifies the degree of association between items and the latent construct they are intended to measure. Meanwhile, discriminant validity demonstrates that a measurement item is not associated with any other latent construct other than the latent construct to be measured.

To test convergent validity, we used three indices, namely, individual factor loading, average variance extracted (AVE), and composite reliability (CR). For individual factor loading and $C R$, the threshold is greater than 0.7, whereas for AVE, it should be greater than 0.5 [60]. The results show that all individual loadings, $\mathrm{AVE}$, and $\mathrm{CR}$ were greater than the minimum recommended value, indicating that there were no issues with the convergent validity of the measurement model in this study.

Table 4. Results for reliability and convergent validity.

\begin{tabular}{|c|c|c|c|c|c|}
\hline Latent Construct & Item & $\begin{array}{l}\text { Factor } \\
\text { Loading }\end{array}$ & $\begin{array}{c}\text { Composite } \\
\text { Reliability (CR) }\end{array}$ & $\begin{array}{l}\text { Average Variance } \\
\text { Extracted (AVE) }\end{array}$ & $\begin{array}{c}\text { Cronbach's } \\
\text { Alpha }\end{array}$ \\
\hline \multirow{3}{*}{ Low usefulness } & lu1 & 0.828 & \multirow{3}{*}{0.904} & \multirow{3}{*}{0.759} & \multirow{3}{*}{0.873} \\
\hline & lu2 & 0.895 & & & \\
\hline & lu3 & 0.889 & & & \\
\hline \multirow{3}{*}{ Functional simplicity } & $\mathrm{fs} 1$ & 0.830 & \multirow{3}{*}{0.896} & \multirow{3}{*}{0.742} & \multirow{3}{*}{0.849} \\
\hline & fs2 & 0.844 & & & \\
\hline & fs3 & 0.908 & & & \\
\hline \multirow{3}{*}{ Perceived inefficiency } & pi1 & 0.835 & \multirow{3}{*}{0.875} & \multirow{3}{*}{0.700} & \multirow{3}{*}{0.786} \\
\hline & pi2 & 0.786 & & & \\
\hline & pi3 & 0.886 & & & \\
\hline \multirow{3}{*}{ Interactivity } & int1 & 0.862 & \multirow{3}{*}{0.851} & \multirow{3}{*}{0.655} & \multirow{3}{*}{0.892} \\
\hline & int2 & 0.778 & & & \\
\hline & int3 & 0.786 & & & \\
\hline
\end{tabular}


Table 4. Cont.

\begin{tabular}{|c|c|c|c|c|c|}
\hline Latent Construct & Item & $\begin{array}{l}\text { Factor } \\
\text { Loading }\end{array}$ & $\begin{array}{c}\text { Composite } \\
\text { Reliability (CR) }\end{array}$ & $\begin{array}{l}\text { Average Variance } \\
\text { Extracted (AVE) }\end{array}$ & $\begin{array}{l}\text { Cronbach's } \\
\text { Alpha }\end{array}$ \\
\hline \multirow{3}{*}{ Experienceability } & $\exp 1$ & 0.904 & \multirow{3}{*}{0.894} & \multirow{3}{*}{0.739} & \multirow{3}{*}{0.764} \\
\hline & $\exp 2$ & 0.839 & & & \\
\hline & exp3 & 0.834 & & & \\
\hline \multirow{3}{*}{ Amplified enjoyment } & ae1 & 0.851 & \multirow{3}{*}{0.907} & \multirow{3}{*}{0.764} & \multirow{3}{*}{0.825} \\
\hline & ae2 & 0.854 & & & \\
\hline & ae3 & 0.916 & & & \\
\hline \multirow{3}{*}{$\begin{array}{c}\text { Personal } \\
\text { innovativeness }\end{array}$} & inno1 & 0.827 & \multirow{3}{*}{0.870} & \multirow{3}{*}{0.691} & \multirow{3}{*}{0.899} \\
\hline & inno2 & 0.888 & & & \\
\hline & inno3 & 0.775 & & & \\
\hline \multirow{3}{*}{$\begin{array}{l}\text { Intention to switch to } \\
\text { AR/VR services }\end{array}$} & swi1 & 0.836 & \multirow{3}{*}{0.894} & \multirow{3}{*}{0.737} & \multirow{3}{*}{0.901} \\
\hline & swi2 & 0.872 & & & \\
\hline & swi3 & 0.867 & & & \\
\hline
\end{tabular}

Finally, discriminant validity was tested by comparing the square root of the AVE and correlation for each latent construct. The square root of the AVE value must be greater than the value of the correlation in the longitudinal and transverse directions to demonstrate discriminant validity. The analysis result shows that the values in bold diagonally are the square root of AVE for each latent construct; these values are greater than all correlation values of the longitudinal and transverse direction, verifying the discriminate validity of the measurement model. Table 5 shows the result of discriminant validity test.

Table 5. Discriminant validity test.

\begin{tabular}{|c|c|c|c|c|c|c|c|c|c|}
\hline & Latent Construct & (1) & (2) & (3) & (4) & (5) & (6) & (7) & (8) \\
\hline (1) & Low usefulness & 0.871 & & & & & & & \\
\hline (2) & Functional simplicity & 0.322 & 0.869 & & & & & & \\
\hline (3) & Perceived inefficiency & 0.214 & 0.300 & 0.837 & & & & & \\
\hline (4) & Interactivity & 0.227 & 0.216 & 0.260 & 0.810 & & & & \\
\hline (5) & Experienceability & 0.196 & 0.251 & 0.347 & 0.313 & 0.860 & & & \\
\hline (6) & Amplified enjoyment & 0.288 & 0.178 & 0.296 & 0.310 & 0.377 & 0.874 & & \\
\hline (7) & Personal innovativeness & 0.258 & 0.250 & 0.178 & 0.415 & 0.361 & 0.229 & 0.831 & \\
\hline (8) & Intention to switch to AR/VR Services & 0.349 & 0.258 & 0.416 & 0.403 & 0.299 & 0.324 & 0.399 & 0.858 \\
\hline
\end{tabular}

Note: The values in bold are the square roots of the AVE values.

\subsection{Structural Model Assessment (Direct Effects H1-H6)}

Using AMOS 22.0, we conducted structural equation modeling (SEM) to evaluate the proposed hypotheses. First, we tested the direct effects $(\mathrm{H} 1-\mathrm{H} 6)$ by formulating SEM. The SEM approach yields two important pieces of information (the standardized path coefficient $(\beta)$ and the squared multiple correlation $\left(R^{2}\right)$ ) for an empirical demonstration of the research model proposed in this study. The path coefficients indicate the strength of the causal relationships between two constructs [61]. Meanwhile, the squared multiple correlation $\left(R^{2}\right)$ indicates the degree of explanatory power explained by the exogenous constructs among the information possessed by the endogenous construct.

First, among the three constructs of the pull effect, low usefulness and functional simplicity, but not perceived inefficiency, were found to have a significant effect on the intention to switch to AR/VR services. Low usefulness had a path coefficient of 0.315 and a $t$-value of 5.227. Functional simplicity had a path coefficient of 0.298 and a $t$-value of 3.954. Thus, H1 and H2 were supported at $p<0.01$. Low usefulness had a greater influence on switching intention to AR/VR contents than functional simplicity. This implies that the reason why users are switching to AR/VR content services is that they recognize the limitation of what they want to do with existing flat contents. In addition, the flat 
contents are functionally simple; therefore, individuals want to switch to AR/VR contents that provide more various functions.

Additionally, the three constructs (interactivity, experienceability, and amplified enjoyment) were found to be significant on the intention to switch to AR/VR services. The standardized path coefficient of interactivity was 0.426 with a $t$-value of 8.520 . Experienceability had a path coefficient of 0.386 with a $t$-value of 6.258 . Therefore, $\mathrm{H} 4$ and $\mathrm{H} 5$ were supported with $p<0.01$. Furthermore, the path coefficient between amplified enjoyment and switching intention to AR/VR contents was 0.299 with a $t$-value of 4.276. Thus, $\mathrm{H} 6$ was supported at $p<0.01$. Among the three pull effects, interactivity had the largest path coefficient, implying that the feature that can interact with the content or other users in the AR/VR environment has the biggest impact on switching to the AR/VR contents. In other words, individuals prefer an environment where they can collaborate on content for their work, rather than simply accepting it. Finally, the analysis of the direct effects shows an $R^{2}$ of 0.659 , implying that six constructs determined $65.9 \%$ of the information exhibited by the endogenous construct (intention to switch to AR/VR contents). Figure 2 presents the results of the direct effects model, and Table 6 summarizes the results of hypothesis testing.

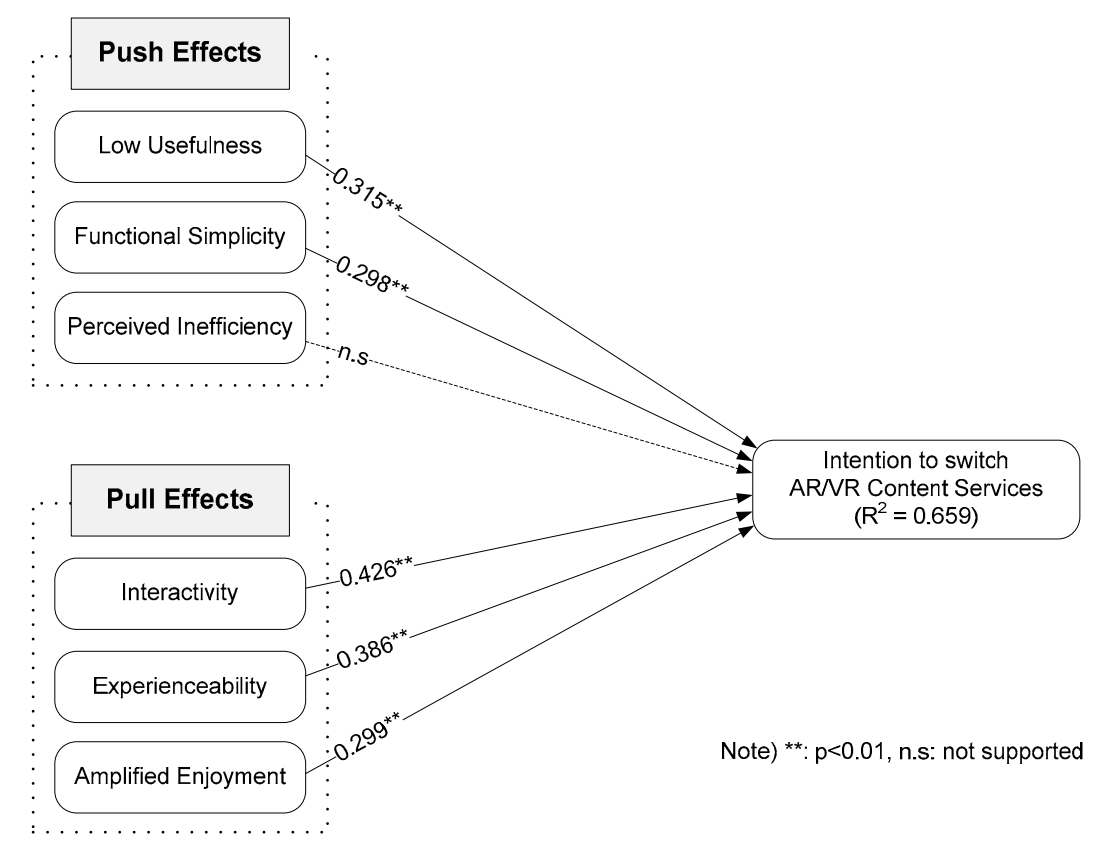

Figure 2. Results of the structural model (direct effects- $\mathrm{H} 1$ to H6).

Table 6. Summary of hypothesis tests (H1-H6).

\begin{tabular}{|c|c|c|c|c|c|c|}
\hline Hypothesis & & Path & & Std. $\beta$ & $t$-Value & Result \\
\hline H1 & Low usefulness & \multirow{6}{*}{$\rightarrow$} & \multirow{6}{*}{$\begin{array}{c}\text { Intention to switch to } \\
\text { mixed reality (MR) } \\
\text { services }\end{array}$} & 0.315 & 5.227 & $S * *$ \\
\hline $\mathrm{H} 2$ & $\begin{array}{c}\text { Functional } \\
\text { simplicity }\end{array}$ & & & 0.298 & 3.954 & $S^{* *}$ \\
\hline $\mathrm{H} 3$ & $\begin{array}{l}\text { Perceived } \\
\text { inefficiency }\end{array}$ & & & 0.094 & 0.853 & NS \\
\hline $\mathrm{H} 4$ & Interactivity & & & 0.426 & 8.520 & $S^{* *}$ \\
\hline H5 & Experienceability & & & 0.386 & 6.258 & $S^{* *}$ \\
\hline H6 & $\begin{array}{l}\text { Amplified } \\
\text { enjoyment }\end{array}$ & & & 0.299 & 4.276 & $S^{* *}$ \\
\hline
\end{tabular}

Note: ${ }^{* *} p<0.01 ;$ S, supported; NS, not supported. 


\subsection{Moderating Effects (H7-H12)}

The moderating effect of personal innovativeness (H7 to H12) was evaluated by F-test using the moderated multiple regression $(M M R)\left(F=\left(\left(R \_2^{\wedge} 2-R \_1 \wedge 2\right) /\left(k \_2-k \_1\right)\right) /\left(\left(1-R \_2{ }^{\wedge} 2\right) /\left(N-k \_2-1\right)\right)\right.$, where $\mathrm{R} \_2{ }^{\wedge} 2=\mathrm{R} 2$ with the interaction term, $\mathrm{R} \_1^{\wedge} 2=\mathrm{R} 2$ without the interaction term, $\mathrm{k} \_1$ and $\mathrm{k} \_2$ denote the number of independent constructs in the model without and with the interaction term, respectively, and $\mathrm{N}$ is the sample size) by Carter and Russell [62]. In MMR, first, we analyzed the model with constructs in the push/pull effects and personal innovativeness as preceding constructs to find the $R^{2}\left(R_{1}^{2}\right)$ of the endogenous construct (intention to switch to AR/VR services). Then, the model with constructs in the push/pull effects, personal innovativeness, and the interaction terms (e.g., low usefulness * personal innovativeness) was analyzed to find the $R^{2}\left(R_{2}^{2}\right)$ of the endogenous construct (intention to switch to AR/VR services). The F-value was calculated based on these $R^{2}$, the differences between two $R^{2}$, the number of independent constructs (degree of freedom: $\mathrm{df}$ ), and the sample size $(\mathrm{N})$ to determine the acceptance of the moderating effects.

For example, H7 considers the moderating effect of personal innovativeness on the relationship between low usefulness and AR/VR service switching intention. To examine H7, first $R_{1}^{2}(0.184)$ is yielded when low usefulness and personal innovativeness are the preceding constructs on switching intention to AR/VR services. Then, the interaction term (low usefulness * personal innovativeness) is added to yield $R_{2}^{2}$ (0.198). Furthermore, the difference between two $R^{2}\left(\Delta R^{2}=0.014\right)$, number of preceding constructs $\left(k_{1}=2, k_{2}=3\right)$, and sample size $(n=465)$ are used to calculate the F-value (8.047). Thus, H7 was significantly supported at $p<0.01$. Figure $3 \mathrm{a}, \mathrm{b}$ illustrates the MMR approach in the case of H7. As a result of testing the remaining moderating effects (H8-H12) in the same way, all other moderating effects except $\mathrm{H} 9$ were significant. These results imply that personal innovativeness plays an important role in the transition of individuals from non-AR/VR content to AR/VR content. Table 7 summarizes the results of the moderating effects.

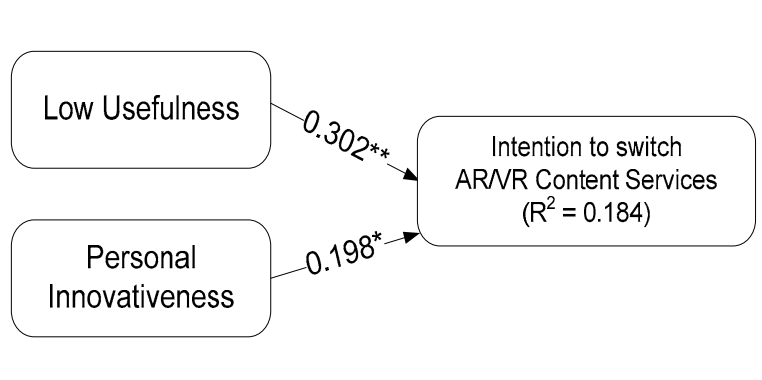

(a)

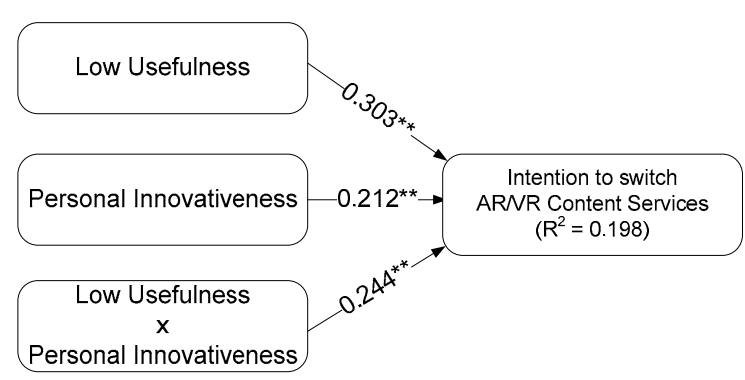

(b)

Figure 3. Results of (a) the direct effect model and (b) the interaction effect model. 
Table 7. Summary of moderating effect tests (H7-H12).

\begin{tabular}{|c|c|c|c|c|c|c|}
\hline $\begin{array}{l}\text { Hypothesis/ } \\
\text { Path }\end{array}$ & Model & $\begin{array}{c}\text { Path } \\
\text { (Std. } \beta / t \text {-Value) }\end{array}$ & $R^{2}$ & $\Delta R^{2}$ & F-Value & Result \\
\hline \multirow{5}{*}{$\begin{array}{c}\text { H7: } \\
\text { LU } \rightarrow \text { SWI } \\
\uparrow \\
\text { INNO }\end{array}$} & \multirow{2}{*}{$\begin{array}{l}\text { No } \\
\text { Interaction }\end{array}$} & $\begin{array}{c}\mathrm{LU} \rightarrow \mathrm{SWI} \\
\left(\beta=0.302 / 4.128^{* *}\right)\end{array}$ & \multirow{2}{*}{0.276} & \multirow{5}{*}{0.014} & \multirow{5}{*}{$8.047^{* *}$} & \multirow{5}{*}{ Supported } \\
\hline & & $\begin{array}{c}\text { INNO } \rightarrow \text { SWI } \\
(\beta=0.198 / 2.001 *)\end{array}$ & & & & \\
\hline & \multirow{3}{*}{ Interaction } & $\begin{array}{c}\mathrm{LU} \rightarrow \mathrm{SWI} \\
\left(\beta=0.303 / 5.718^{* *}\right)\end{array}$ & \multirow{3}{*}{0.305} & & & \\
\hline & & $\begin{array}{c}\text { INNO } \rightarrow \text { SWI } \\
\left(\beta=0.212 / 3.886^{* *}\right)\end{array}$ & & & & \\
\hline & & $\begin{array}{c}\mathrm{LU} \times \mathrm{INNO} \rightarrow \mathrm{SWI} \\
\left(\beta=0.244 / 3.872^{* *}\right)\end{array}$ & & & & \\
\hline \multirow{5}{*}{$\begin{array}{c}\text { H8: } \\
\text { FS } \rightarrow \text { SWI } \\
\uparrow \\
\text { INNO }\end{array}$} & \multirow{2}{*}{$\begin{array}{l}\text { No } \\
\text { Interaction }\end{array}$} & $\begin{array}{c}\text { FS } \rightarrow \text { SWI } \\
\left(\beta=0.284 / 4.563^{* *}\right)\end{array}$ & \multirow{2}{*}{0.298} & \multirow{5}{*}{0.019} & \multirow{5}{*}{$11.201 * *$} & \multirow{5}{*}{ Supported } \\
\hline & & $\begin{array}{c}\text { INNO } \rightarrow \text { SWI } \\
\left(\beta=0.200 / 1.995^{*}\right)\end{array}$ & & & & \\
\hline & \multirow{3}{*}{ Interaction } & $\begin{array}{c}\text { FS } \rightarrow \text { SWI } \\
\left(\beta=0.289 / 5.123^{* *}\right)\end{array}$ & \multirow{3}{*}{0.315} & & & \\
\hline & & $\begin{array}{c}\text { INNO } \rightarrow \text { SWI } \\
\left(\beta=0.208 / 3.552^{* *}\right)\end{array}$ & & & & \\
\hline & & $\begin{array}{l}\mathrm{FS} \times \mathrm{INNO} \rightarrow \mathrm{SWI} \\
\left(\beta=0.236 / 4.007^{* *}\right)\end{array}$ & & & & \\
\hline \multirow{5}{*}{$\begin{array}{c}\text { H9: } \\
\text { PI } \rightarrow \text { SWI } \\
\uparrow \\
\text { INNO }\end{array}$} & \multirow{2}{*}{$\begin{array}{l}\text { No } \\
\text { Interaction }\end{array}$} & $\begin{array}{c}\text { PI } \rightarrow \text { SWI } \\
(\beta=0.099 / 1.001)\end{array}$ & \multirow{2}{*}{0.147} & \multirow{5}{*}{0.004} & \multirow{5}{*}{2.172} & \multirow{5}{*}{$\begin{array}{c}\text { Not } \\
\text { Supported }\end{array}$} \\
\hline & & $\begin{array}{c}\text { INNO } \rightarrow \text { SWI } \\
(\beta=0.176 / 2.169 *)\end{array}$ & & & & \\
\hline & \multirow{3}{*}{ Interaction } & $\begin{array}{c}\mathrm{PI} \rightarrow \mathrm{SWI} \\
(\beta=0.127 / 1.132)\end{array}$ & \multirow{3}{*}{0.151} & & & \\
\hline & & $\begin{array}{c}\text { INNO } \rightarrow \text { SWI } \\
(\beta=0.186 / 1962 *)\end{array}$ & & & & \\
\hline & & $\begin{array}{l}\mathrm{PI} \times \mathrm{INNO} \rightarrow \mathrm{SWI} \\
\left(\beta=0.194 / 2.204^{*}\right)\end{array}$ & & & & \\
\hline \multirow{5}{*}{$\begin{array}{c}\text { H10: } \\
\text { INT } \rightarrow \text { SWI } \\
\uparrow \\
\text { INNO }\end{array}$} & No & $\begin{array}{c}\text { INT } \rightarrow \text { SWI } \\
\left(\beta=0.427 / 8.653^{* *}\right)\end{array}$ & \multirow{2}{*}{0.292} & \multirow{5}{*}{0.015} & \multirow{5}{*}{$9.978^{* *}$} & \multirow{5}{*}{ Supported } \\
\hline & Interaction & $\begin{array}{c}\text { INNO } \rightarrow \text { SWI } \\
\left(\beta=0.210 / 3.064^{* *}\right)\end{array}$ & & & & \\
\hline & \multirow{3}{*}{ Interaction } & $\begin{array}{c}\text { INT } \rightarrow \text { SWI } \\
\left(\beta=0.439 / 9.101^{* *}\right)\end{array}$ & \multirow{3}{*}{0.307} & & & \\
\hline & & $\begin{array}{c}\text { INNO } \rightarrow \text { SWI } \\
\left(\beta=0.248 / 4.253^{* *}\right)\end{array}$ & & & & \\
\hline & & $\begin{array}{c}\mathrm{INT} \times \mathrm{INNO} \rightarrow \mathrm{SWI} \\
\left(\beta=0.229 / 3.723^{* *}\right)\end{array}$ & & & & \\
\hline
\end{tabular}


Table 7. Cont.

\begin{tabular}{|c|c|c|c|c|c|c|}
\hline $\begin{array}{l}\text { Hypothesis/ } \\
\text { Path }\end{array}$ & Model & $\begin{array}{c}\text { Path } \\
\text { (Std. } \beta / t \text {-Value) }\end{array}$ & $R^{2}$ & $\Delta R^{2}$ & F-Value & Result \\
\hline \multirow{5}{*}{$\begin{array}{c}\text { H11: } \\
\text { EXP } \underset{\uparrow}{\rightarrow} \text { SWI } \\
\uparrow \\
\text { INNO }\end{array}$} & \multirow{2}{*}{$\begin{array}{c}\text { No } \\
\text { Interaction }\end{array}$} & $\begin{array}{c}\text { EXP } \rightarrow \text { SWI } \\
\left(\beta=0.387 / 5.436^{* *}\right)\end{array}$ & \multirow{2}{*}{0.287} & \multirow{5}{*}{0.029} & \multirow{5}{*}{$19.545^{* *}$} & \multirow{5}{*}{ Supported } \\
\hline & & $\begin{array}{c}\text { INNO } \rightarrow \text { SWI } \\
\left(\beta=0.239 / 3.123^{* *}\right)\end{array}$ & & & & \\
\hline & \multirow{3}{*}{ Interaction } & $\begin{array}{c}\mathrm{EXP} \rightarrow \mathrm{SWI} \\
\left(\beta=0.398 / 6.071^{* *}\right)\end{array}$ & \multirow{3}{*}{0.316} & & & \\
\hline & & $\begin{array}{c}\text { INNO } \rightarrow \text { SWI } \\
\left(\beta=0.231 / 3.540^{* *}\right)\end{array}$ & & & & \\
\hline & & $\begin{array}{l}\mathrm{EXP} \times \mathrm{INNO} \rightarrow \mathrm{SWI} \\
\quad\left(\beta=0.280 / 3.953^{* *}\right)\end{array}$ & & & & \\
\hline \multirow{5}{*}{$\begin{array}{c}\text { H12: } \\
\mathrm{AE} \rightarrow \text { SWI } \\
\uparrow \\
\text { INNO }\end{array}$} & \multirow{2}{*}{$\begin{array}{c}\text { No } \\
\text { Interaction }\end{array}$} & $\begin{array}{c}\mathrm{AE} \rightarrow \mathrm{SWI} \\
\left(\beta=0.310 / 5.951^{* *}\right)\end{array}$ & \multirow{2}{*}{0.214} & \multirow{5}{*}{0.018} & \multirow{5}{*}{$10.805^{* *}$} & \multirow{5}{*}{ Supported } \\
\hline & & $\begin{array}{c}\text { INNO } \rightarrow \text { SWI } \\
\left(\beta=0.211 / 3.059^{* *}\right)\end{array}$ & & & & \\
\hline & \multirow{3}{*}{ Interaction } & $\begin{array}{c}\mathrm{AE} \rightarrow \mathrm{SWI} \\
\left(\beta=0.310 / 5.664^{* *}\right)\end{array}$ & \multirow{3}{*}{0.232} & & & \\
\hline & & $\begin{array}{c}\text { INNO } \rightarrow \text { SWI } \\
\left(\beta=0.216 / 3.820^{* *}\right)\end{array}$ & & & & \\
\hline & & $\begin{array}{l}\mathrm{AE} \times \mathrm{INNO} \rightarrow \mathrm{SWI} \\
\left(\beta=0.242 / 3.771^{* *}\right)\end{array}$ & & & & \\
\hline
\end{tabular}

Note: ${ }^{*} p<0.05 ;{ }^{* *} p<0.01$; LU, low usefulness; FS, functional simplicity; PI, perceived inefficiency; INT, interactivity; EXP, experienceability; AE, amplified enjoyment; INNO, personal innovativeness; SWI, intention to switch to AR/VR content services.

\section{Conclusions and Implications}

\subsection{Summary of Results}

The rapid development of IT in the fourth industrial revolution has caused a great change in the use of contents by individuals. In addition, the content industry is rapidly changing to dynamic content based on IT. Therefore, this study tries to find the empirical proof that explains the main reasons why individuals switch their content use from existing flat contents to AR/VR contents to experience contents with variability and dynamics. Following the push/pull theory used in various literature focusing on switching, this study develops a research model to investigate individuals' switching intention to AR/VR contents. In the proposed research model, we put forward three limitations of flat contents (low usefulness, functional simplicity, and perceived inefficiency) as the push effects and three strengths of AR/VR contents (interactivity, experienceability, and amplified enjoyment) as the pull effects based on the literature and responses of users who switched to AR/VR content services. We also proposed personal innovativeness as a mooring effect between push and pull effects and AR/VR content conversion.

Using a survey method, we collected data from 465 AR/VR content users who switched from flat contents. Then, the proposed research model was evaluated using SEM. The results of this study are as follows. First, only two constructs in the push effects, with the exception of perceived inefficiency, had a significant impact on the intention to switch to AR/VR content services. Low usefulness and functional simplicity had standardized coefficients 0.315 ( $t$-value 5.227) and 0.298 ( $t$-value 3.954), respectively. Thus, $\mathrm{H} 1$ and $\mathrm{H} 2$ were supported at $p<0.01$. These results imply that content users agree that flat contents are not only functionally limited but also less useful for users' work. Prior studies [27,63] argued that individuals use online contents for various purposes, but if those contents are static and simple, users will not perceive them as useful contents for their main use, and they will search for 
newer contents. However, perceived inefficiency was not supported; hence, H3 was rejected. From the $\mathrm{H} 3$ results, it can be inferred that content users place more emphasis on external factors such as content design than on the efficiency of the content details. In other words, users do not have much interest in content efficiency to achieve their goals from flat content. These findings are consistent with the literature [27-29] in the respect that flat contents are based on two dimensions, resulting from the lack of variety and dynamics. These contents are very simple and often minimize the usefulness when users are trying to do what they want to do.

Second, three constructs in the pull effects had a significant impact on switching intention to AR/VR content services. The path coefficient between interactivity and intention to switch to AR/VR content services was 0.426 ( $t$-value 8.520 ). Thus, $\mathrm{H} 4$ was supported at $p<0.01$. Exprienceability and amplified enjoyment had standardized coefficients of 0.386 ( $t$-value 6.258) and 0.299 ( $t$-value 4.276), respectively. Thus, $\mathrm{H} 5$ and $\mathrm{H} 6$ were supported at $p<0.01$. These results reaffirm the importance of AR/VR content features to the users, as highlighted in previous studies. For example, Chung et al. [40] argued that in AR/VR environments, individuals can interact with contents added in either real or virtual environments, allowing them to have a higher positive perception of AR/VR contents. Once individuals form such a positive perception of AR/VR contents, their switching intention becomes much higher. In addition, unlike flat content, users can experience a given situation through AR/VR contents, which makes their job much more effective. For example, if individuals use AR/VR contents for design purposes, they can both make a three-dimensional blueprint and see how the actual outputs come out. That is, since users can be a part of AR/VR contents, not simply accepting them, the intention of the user to switch to the content service can be remarkable. Other studies [42] also found that being able to experience contents in an AR/VR environment causes greater switching intention among individuals. Finally, the findings of the study reveal that individuals feel more enjoyment with AR/VR contents, resulting in the switch. In this regard, content users not only constantly find content suitable for their purpose but also seek content that is easier to use and more enjoyable. For now, greater enjoyment of content usage is only possible with AR/VR content. Certain AR/VR content is even so realistic that users obtain the same enjoyment as in real life, which makes them move to AR/VR contents [41].

Finally, personal innovativeness has been shown to enhance the relationship between the six variables in the push/pull effects and AR/VR content service switching intention, except for the path between perceived efficiency and intention to switch to AR/VR content services. These results suggest that innovative individuals are very willing to switch to new technologies for content use, and their innovations play an important role when the limitations of traditional content services or the advantages of new content services (AR/VR) are apparent. Prior studies $[49,52]$ found the importance of personal innovativeness as a moderator to explain individuals' behaviors in various contexts of IT.

\subsection{Implications}

Based on the study findings, we yield some important implications. First, the data collected in this study suggest that individuals of all ages and various occupations use AR/VR contents for diverse purposes. Based on these demographic data, the importance of research on AR/VR contents can be clearly seen. Second, this study is significant in that it not only developed a research theory to empirically study the behavior of content users in using AR/VR content but also proved the validity of the developed research theory. Additionally, PPM is known to be useful for explaining individuals' migration. This study has an important theoretical contribution by confirming that the PPM framework is a model that can sufficiently aid the research on AR/VR content services. Another contribution of this study is related to fulfilling the research gaps in AR/VR contents. Prior studies on AR/VR contents have focused on prospects from a technical perspective. However, for a more accurate understanding of the use of AR/VR content, research on the user should be a top priority. Only then can users develop and deliver the content services they want more efficiently. From this point of view, the results of this 
study provide reasonable information to simultaneously understand the perception of flat content and AR/VR content.

In addition to academic implications, the results of this study also provide some practical implications. First, through the obtained results, AR/VR content firms can better understand what to emphasize in content development. For example, regardless of the type of content, individuals prefer content with greater enjoyment and experience. Therefore, even if a firm creates educational content, it still needs to provide fun and interactive AR/VR content services. In other words, this study makes it clear that content creation should be done from the user's point of view, not from the developer's point of view. Second, the results of this study provide a marketing strategy for AR/VR content developers and service providers as innovative individuals have a higher tendency to switch to AR/VR content than non-innovative users. Thus, they can aggressively target highly innovative content users. Finally, in the rapid change from the use of flat content to AR/VR content, the results of this study provide some indications for content development companies on what should remain as flat contents and what should be developed as AR/VR content. In other words, from the two perspectives of push and pull, the existing flat content may be more suitable than the AR/VR content for the simple absorption-type content or the age when the content should be simple regardless of work.

Although this study offers various implications, some limitations should be addressed for further investigation. First, this study included a limited number of external constructs categorized into the push/pull effects and the mooring effect affecting individuals' switching intention to AR/VR content services. Thus, future studies should review more literature and examine other factors for push/pull and mooring effects. Second, this study only investigated individuals' intention to switch to AR/VR contents. However, whether intention leads to the actual switch action is still not verified; therefore, further research is needed to investigate whether individuals having AR/VR content switching intention leads to the actual behavior. Finally, each latent construct in the research model was assessed with three to four measures, which may limit the validity of measures. Therefore, more measures to test latent constructs need to be developed and verified in the future.

Author Contributions: As the main contributors, S.K. and M.J.C. outlined and collected the data, conducted the first round of analysis and discussion, and performed the literature review. J.S.C. reorganized the manuscript, conducted an additional literature review, conceptualized the work, research design, and discussion, and completed a reference check. All authors have read and agreed to the published version of the manuscript.

Funding: This research received no external funding.

Conflicts of Interest: The authors declare no conflicts of interest.

\section{References}

1. Lee, J.; Suh, K.; Nam, S. CPND Ecosystem-based Broadcasting/Media Virtual Reality (VR) Prospects. J. Broadcast Eng. 2018, 23, 19-25. [CrossRef]

2. Kang, J. Effect of Interaction Based on Augmented Context in Immersive Virtual Reality Environment. Wirel. Pers. Commun. 2018, 98, 1931-1940. [CrossRef]

3. Statista. Forecast for the Number of Active Virtual Reality Users Worldwide from 2014 to 2018 (in Millions); Statista: Hamburg, Germany, 2017.

4. Zion Market Research. Virtual Reality (VR) Market to Report Impressive Growth, Revenue to Surge to US $\$ 26.89$ Billion by 2022; Zion Market Research: Maharashtra, India, 2018.

5. Guttentag, D.A. Virtual Reality: Applications and Implications for Tourism. Tour. Manag. 2010, 31, 637-651. [CrossRef]

6. Ong, S.K.; Yuan, M.L.; Nee, A.Y.C. Augmented Reality Applications in Manufacturing: A Survey. Int. J. Prod. Res. 2008, 46, 2707-2742. [CrossRef]

7. Fagan, M.; Kilmon, C.; Pandey, V. Exploring the Adoption of a Virtual Reality Simulation. Campus-Wide Inf. Syst. 2012, 29, 117-127. [CrossRef]

8. Rose, T.; Nam, C.S.; Chen, K.B. Immersion of Virtual Reality for Rehabilitation-Review. Appl. Ergon. 2018, 69, 153-161. [CrossRef] 
9. Noh, K.-H.; Jee, H.-K.; Lim, S. Effect of Augmented Reality Contents Based Instruction on Academic Achievement, Interest and Flow of Learning. J. Korea Contents Assoc. 2010, 10, 1-13. [CrossRef]

10. Nee, A.Y.; Ong, S.K.; Chryssolouris, G.; Mourtzis, D. Augmented Reality Applications in Design and Manufacturing. CIRP Ann. 2012, 61, 657-679. [CrossRef]

11. Han, J.W. A Study on Effects of AR and VR Assisted Lessons on Immersion in Learning and Academic Stress. Int. J. Internet Broadcast. Commun. 2018, 10, 19-24. [CrossRef]

12. An, S.-H.; Lee, C.-K. A Study on the Influence of Sense of Virtual Reality Contents on Experiential Value, Satisfaction and Visit Intention. J. Tour. Sci. 2019, 43, 135-149. [CrossRef]

13. Ravenstein, E. The Laws of Migration. J. Stat. Soc. 1885, 48, 167-235. [CrossRef]

14. Lee, E.S. A Theory of Migration. Demography 1966, 3, 47-57. [CrossRef]

15. Bansal, H.S.; Taylor, S.F.; James, Y.S. Migrating to New Service Provider: Toward a Unifying Framework of Consumers' Switching Behaviors. J. Acad. Mark. Sci. 2005, 33, 96-115. [CrossRef]

16. Bogue, D.J. A Migrant's-Eye View of the Costs and Benefits of Migration to a Metropolis Internal Migration: A Comparative Perspective; Academic Press: New York, NY, USA, 1977.

17. Moon, B. Paradigms in Migration Research: Exploring 'Mooring' as a Schema. Prog. Hum. Geogr. 1995, 19, 504-524. [CrossRef] [PubMed]

18. Chang, H.H.; Wong, K.H.; Li, S.Y. Applying Push-Pull-Mooring to Investigate Channel Switching Behaviors: M-Shopping Self-Efficacy and Switching Costs as Moderators. Electron. Commer. Res. Appl. 2017, 24, 50-67. [CrossRef]

19. Cheng, S.; Lee, S.J.; Choi, B. An Empirical Investigation of Users' Voluntary Switching Intention for Mobile Personal Cloud Storage Services Based on the Push-Pull-Mooring Framework. Comput. Hum. Behav. 2019, 92, 198-215. [CrossRef]

20. Sun, Y.; Liu, D.; Chen, S.; Wu, X.; Shen, X.-L.; Zhang, X. Understanding Users' Switching Behavior of Mobile Instant Messaging Applications: An Empirical Study from the Perspective of Push-Pull-Mooring Framework. Comput. Hum. Behav. 2017, 75, 727-738. [CrossRef]

21. Wang, L.; Luo, X.R.; Yang, X.; Qiao, Z. Easy Come or Easy Go? Empirical Evidence on Switching Behaviors in Mobile Payment Applications. Inf. Manag. 2019, 56, 103-150. [CrossRef]

22. Hsieh, J.K.; Hsieh, Y.C.; Chiu, H.C.; Feng, Y.C. Post-Adoption Switching Behavior for Online Service Substitutes: A Perspective of the Push-Pull-Mooring Framework. Comput. Hum. Behav. 2012, 28, 1912-1920. [CrossRef]

23. Bhattacherjee, A.; Hikmet, N. Physicians' Resistance toward Healthcare Information Technology: A Theoretical Model and Empirical Test. Eur. J. Inf. Syst. 2007, 16, 725-737. [CrossRef]

24. Laumer, S.; Eckhardt, A. Why do People Reject Technologies: A Review of User Resistance Theories. In Information Systems Theory; Springer: New York, NY, USA, 2012; pp. 63-86.

25. Alter, S. Work System Theory: Overview of Core Concepts, Extensions, and Challenges for the Future. J. Assoc. Inf. Syst. 2013, 14, 72-121. [CrossRef]

26. Lapointe, L.; Rivard, S. A Multilevel Model of Resistance to Information Technology Implementation. MIS Q. 2005, 29, 461-491. [CrossRef]

27. Permatasari, C.L.; Prajanti, S.D.W. Acceptance of Financial Accounting Information System at Schools: Technology Acceptance Model. J. Econ. Educ. 2018, 7, 109-120. [CrossRef]

28. Bolz, N. The Use-illusion of the World: On the Meaning of Design for the Economy and Society in the Computer Age. Mediamatic 1998, 9, 61.

29. Maican, C.; Lixandroiu, R. A System Architecture Based on Open Source Enterprise Content Management Systems for Supporting Educational Institutions. Int. J. Inf. Manag. 2016, 36, 207-214. [CrossRef]

30. Maslach, C.; Jackson, S.E.; Leiter, M.P.; Schaufeli, W.B.; Schwab, R.L. Maslach Burnout Inventory; Consulting Psychologists Press: Palo Alto, CA, USA, 1986; Volume 21, pp. 3463-3464.

31. Yew Wong, C.; Johansen, J. A Framework of Manufacturer-Retailer Coordination Process: Three Case Studies. Int. J. Retail Distrib. Manag. 2008, 36, 387-408. [CrossRef]

32. Trappey, A.J.; Trappey, C.V. Global Content Management Services for Product Providers and Purchasers. Comput. Ind. 2004, 53, 39-58. [CrossRef]

33. Mujber, T.S.; Szecsi, T.; Hashmi, M.S. Virtual Reality Applications in Manufacturing Process Simulation. J. Mater. Process. Technol. 2004, 155, 1834-1838. [CrossRef] 
34. Hou, A.C.; Chern, C.C.; Chen, H.G.; Chen, Y.C. Migrating to a New Virtual World: Exploring MMORPG Switching through Human Migration Theory. Comput. Hum. Behav. 2011, 27, 1892-1903. [CrossRef]

35. Khan, B.H.; Vega, R. Factors to Consider When Evaluating a Web-based Instruction Course: A Survey. In Web-Based Instruction; Khan, B.H., Ed.; Educational Technology: Englewood Cliffs, NJ, USA, 1999; pp. 375-379.

36. Reeves, T.C.; Reeves, P.M. Effective Dimensions of Interactive Learning on the World Wide Web. In Web-Based Instruction; Khan, B.D., Ed.; Educational Technology: Englewood Cliffs, NJ, USA, 1997.

37. Bruckman, A.; Jensen, C. The Mystery of the Death of MediaMOO: Seven Years of Evolution of an Online Community'. In Building Virtual Communities: Learning and Change in Cyberspace; Renninger, K.A., Shumar, W., Eds.; Cambridge University Press: New York, NY, USA, 2002; pp. 21-33.

38. Ha, L.; James, E.L. Interactivity Reexamined: A Baseline Analysis of Early Business Web Sites. J. Broadcast. Electron. Media 1998, 42, 457-474. [CrossRef]

39. Merrilees, B. Interactivity Design as the Key to Managing Customer Relations in e-Commerce. J. Relatsh. Mark. 2002, 1, 111-126. [CrossRef]

40. Chung, N.; Han, H.; Joun, Y. Tourists' Intention to Visit a Destination: The Role of Augmented Reality (AR) Application for a Heritage Site. Comput. Hum. Behav. 2015, 50, 588-599. [CrossRef]

41. Formsma, K. ParabolaX: Learner Engagement with Serious Games. Master's Thesis, Grand Valley State University, Allendale, MI, USA, 2013; p. 150.

42. Market Advisor. 4 Reasons for B2B Marketers to Score with AR/VR in 2018 . Available online: https://www.martechadvisor.com/articles/customer-experience-2/4-reasons-for-b2b-marketers-toscore-with-arvr-in-2018 (accessed on 14 October 2019).

43. Zhang, J.; Mao, E. Understanding the Acceptance of Mobile SMS Advertising Among Young Chinese Consumers. Psychol. Mark. 2008, 25, 787-805. [CrossRef]

44. Zhang, L.; Zhu, J.; Liu, Q. A Meta-Analysis of Mobile Commerce Adoption and the Moderating Effect of Culture. Comput. Hum. Behav. 2012, 28, 1902-1911. [CrossRef]

45. Nysveen, H.; Pedersen, P.E.; Thorbjørnsen, H. Intentions to Use Mobile Services: Antecedents and Cross-Service Comparisons. J. Acad. Mark. Sci. 2005, 33, 330-346. [CrossRef]

46. Hwang, Y.; Kim, D.J. Customer Self-Service Systems: The Effects of Perceived Web Quality with Service Contents on Enjoyment, Anxiety and E-Trust. Decis. Support Syst. 2007, 43, 746-760. [CrossRef]

47. Agarwal, R.; Karahanna, E. Time Flies When You're Having Fun: Cognitive Absorption and Beliefs about Information Technology Usage. MIS Q. 2000, 24, 665-693. [CrossRef]

48. Wu, J.H.; Wang, S.C. What Drives M-commerce? An Empirical Evaluation of the Revised Technology Acceptance Model. Inf. Manag. 2005, 42, 719-729. [CrossRef]

49. Whyte, J. Innovation and Users: Virtual Reality in the Construction Sector. Constr. Manag. Econ. 2003, 21, 565-572. [CrossRef]

50. Lu, Y.; Cao, Y.; Wang, B.; Yang, S. A Study on Factors that Affect Users' Behavioral Intention to Transfer Usage from the Offline to the Online Channel. Comput. Hum. Behav. 2011, 27, 355-364. [CrossRef]

51. Park, S.C.; Ryoo, S.Y. An Empirical Investigation of End-Users' Switching Toward Cloud Computing: A Two Factor Theory Perspective. Comput. Hum. Behav. 2013, 29, 160-170. [CrossRef]

52. Lee, J.; Lee, J.-N. Understanding the Product Information Inference Process in Electronic Word-of-Mouth: An Objectivity-Subjectivity Dichotomy Perspective. Inf. Manag. 2009, 46, 302-311. [CrossRef]

53. Lii, Y.S.; Lim, H.J.; Tseng, L.P.D. The Effects of Web Operational Factors on Marketing Performance. J. Am. Acad. Bus. 2004, 5, 486-494.

54. Xu, Y.C.; Yang, Y.; Cheng, Z.; Lim, J. Retaining and Attracting Users in Social Networking Services: An Empirical Investigation of Cyber Migration. J. Strateg. Inf. Syst. 2014, 23, 239-253. [CrossRef]

55. Zhang, K.Z.; Cheung, C.M.; Lee, M.K. Online Service Switching Behavior: The Case of Blog Service Providers. J. Electron. Commer. Res. 2012, 13, 184.

56. Bentler, P.M. Comparative Fit Indexes in Structural Models. Psychol. Bull. 1990, 107, 238-246. [CrossRef]

57. Browne, M.W.; Cudeck, R. Alternative Ways of Assessing Model Fit. In Testing Structural Equation Models; Bollen, K.A., Long, J.S., Eds.; Sage: Newbury Park, CA, USA, 1993; pp. 136-162.

58. Goodhue, D.L. Understanding User Evaluations of Information Systems. Manag. Sci. 1995, 41, 1827-1844. [CrossRef]

59. Fornell, C.; Larcker, D.F. Evaluating Structural Equation Models with Unobservable Variables and Measurement Error. J. Mark. Res. 1981, 18, 39-50. [CrossRef] 
60. Carmines, E.G.; Zeller, R.A. Reliability and Validity Assessment; SAGE University Paper Series on Quantitative Applications in the Social Sciences; Sage: Beverly Hills, CA, USA, 1979; pp. 7-17.

61. Wixom, B.H.; Watson, H.J. An Empirical Investigation of the Factors Affecting Data Warehousing Success. MIS Q. 2001, 25, 17-41. [CrossRef]

62. Carte, T.A.; Russell, C.J. In Pursuit of Moderation: Nine Common Errors and Their Solutions. MIS Q. 2003, 27, 479-501. [CrossRef]

63. Murawski, M. Virtual Reality as a Potential Marketing Tool in the Tourism Industry. Bachelor's Thesis, Berlin School of Economics and Law, Berlin, Germany, 8 March 2017.

(C) 2019 by the authors. Licensee MDPI, Basel, Switzerland. This article is an open access article distributed under the terms and conditions of the Creative Commons Attribution (CC BY) license (http://creativecommons.org/licenses/by/4.0/). 